\title{
Governo Lacerda versus Cinema Novo: A grande cidade como arena de debates simbólicos
}

\author{
Lacerda's administration versus Cinema Novo: \\ A grande cidade as an arena of symbolic struggles
}

Carlos Eduardo Pinto

\section{Cinema Novo, Rio, sertão}

Neste artigo procuro deslindar alguns aspectos da representação do Rio de Janeiro pelo Cinema Novo através da análise de $A$ grande cidade (1966), segundo longa- metragem de Cacá Diegues. O Cinema Novo, considerado a primeira experiência brasileira de cineastas pertencentes à mesma geração (Xavier, 2001), era formado por Diegues e, entre outros, Glauber Rocha, Joaquim Pedro de Andrade, Ruy Guerra, Paulo César Saraceni, Leon Hirszman e Gustavo Dahl. Nelson Pereira dos Santos, mais velho e com uma carreira já iniciada, era uma das inspirações, e terminou por compor o movimento também.

Carlos Eduardo Pinto é doutorando em História da Universidade Federal Fluminense (UFF), Rio de Janeiro, Brasil, e bolsista CAPES (dudachacon@yahoo.com.br).

Este artigo é derivado de um dos capítulos da tese do autor, em fase de conclusão, intitulada "Imaginar a cidade real: a representação do Rio de Janeiro pelo Cinema Novo na década de 1960".

Artigo recebido em 31 de dezembro de 2012 e aprovado para publicação em $1^{\circ}$ de abril de 2013.

Est. Hist., Rio de Faneiro, vol. 26, no 51, p. 154-172, janeiro-junho de 2013. 
Os jovens coetâneos, marcados pelo golpe que instaurou a ditadura civil-militar - o que permite alocá-los na "geração de 1964" (Rollemberg, 1999: 50) -, também se apropriaram dos movimentos reformistas do início da década. Vinculados às esquerdas através de partidos ou associações, buscavam construir um estilo cinematográfico não canonizado pela narrativa clássica hollywoodiana identificada com o neoimperialismo norte-americano - para enfocar o "homem do povo", depositário da nacionalidade brasileira e alvo de conscientização.

A busca de uma relação entre o Cinema Novo e um locus - assim como se associa a Nouvelle Vague a Paris e o Neorrealismo a Roma - apontaria para o sertão e para o Rio. Contudo, apesar da importância do primeiro, o movimento nunca foi classificado como "sertanejo", e sim associado ao gentílico "carioca". Pode-se defender que isso se deveu unicamente ao pertencimento de seus componentes à cidade, por nascimento ou opção, porém acredito que os liames com $o$ Rio ultrapassem tal esfera. Eles denotam igualmente a escolha intencional de representar uma urbe cujo imaginário - indissociável de sua capitalidade (Motta, 2004) - também servia ao discurso cinemanovista.

Tal processo de representação do Rio ganha relevo quando se atenta para alguns aspectos da criação cinemanovista, sobretudo o movimento de apropriação que os jovens cineastas fizeram de Rio, 40 graus (Nelson P. dos Santos, 1955). Considerado o inaugurador do cinema moderno no Brasil e uma representação realista bem-sucedida das favelas cariocas, o filme funcionou como um incentivo à formação do movimento. Como contraponto, estava a rejeição de Orfeu negro (Orphée noir, Marcel Camus, 1959), coprodução franco-ítalo-brasileira de grande repercussão internacional, considerada pelos cinemanovistas uma visão superficial e pitoresca das favelas. Logo, tais obras se tornaram balizas de criação, numa dupla interlocução percebida timidamente na obra coletiva Cinco vezes favela (1962) e mais explícita no filme analisado aqui, sobretudo no que se refere à rejeição de Orfeu negro (Coelho, 2008).

Apesar da importância do que aponto acima, o diálogo de $A$ grande cidade com outras produções é ainda mais amplo. $O$ filme foi realizado um ano após a consagração internacional do Cinema Novo, em 1964, quando três obras estilisticamente muito marcantes, todas possuindo temática sertaneja, tiveram grande destaque em festivais fora do país. A repercussão de Deus e o diabo na Terra do Sol (Glauber Rocha, 1964), Vidas secas (Nelson P. dos Santos, 1963) e Os fuzis (Ruy Guerra, 1964) ajudou a consolidar o sertão como espaço privilegiado pelo movimento. Por outro lado, o filme de Cacá é contemporâneo de $O$ desafio (Paulo C. Saraceni, 1965), obra de grande impacto sobre os cinemanovistas, entre outros motivos por ter realizado uma representação do Rio que prescindia da exibição dos espaços comumente associados à exclusão social, como as favelas. $A$ grande cidade, por sua vez, realiza uma representação da ex-capital através de persona- 


\section{Carlos Eduardo Pinto}

gens que são migrantes nordestinos, alguns favelados, mas também se interessa pelo fenômeno urbano para além dos espaços de exclusão. Poderia ser considerado, portanto, uma síntese das possibilidades apresentadas pelo movimento até então.

Ainda no âmbito da representação do sertão e da cidade, é importante frisar que nos anos 1960 vigorava, mesmo que atenuada, uma disputa simbólica entre esses dois universos no campo cinematográfico. A cidade era considerada espaço de alienação e desenraizamento, enquanto o sertão (ou, de forma mais ampla, o interior) era visto como espaço de tradição, mais próximo da "pureza" da nacionalidade (Bernardet e Galvão, 1983; Ramos, 2005). O maior interesse aqui recai sobre o fato de que tal disputa se resolve harmoniosamente no filme de Diegues, através da mobilização de redes culturais que permitem aproximar o sertão de alguns aspectos da capitalidade carioca.

Como afirmou Diegues a respeito de seu processo criativo, o filme era uma tentativa de fazer um "acerto de contas" com o fascínio que a cidade exercia sobre ele desde sua chegada de Alagoas, ainda criança (Oroz, 1984: 36). Enquanto cursava Direto na PUC - sem nunca vir a exercer a profissão - Cacá fundou cineclubes e realizou curtas amadores. Na mesma época, passou a dirigir o jornal $O$ Metropolitano, da União Nacional dos Estudantes (UNE) e, concomitantemente, participou do Centro Popular de Cultura (CPC). Esse importante espaço de socialização de jovens artistas, inclusive cineastas, era fortemente identificado com o Instituto Superior de Estudos Brasileiros (ISEB) no que se referia à crença na possibilidade de utilizar a arte como forma de conscientização política. Apesar de concordar com tal proposta, Cacá se mostrava avesso à ideia de instrumentalização política da arte, defendendo que a politização não deveria se opor à estética, como propunham alguns membros do CPC.

Por fim, antes de passar à análise fílmica é importante frisar que a formação do Cinema Novo é contemporânea da inauguração de Brasília, em 1960. Após perder o posto de capital, o Rio foi transformado em um novo ente da Federação, batizado de estado da Guanabara. O governo de Carlos Lacerda (1960-1965), primeiro da nova unidade e durante o qual Cacá realizou $A$ grande cidade, foi dedicado a provar que, se a Novacap (Brasília) tinha o modernismo como trunfo, a Belacap (Guanabara) possuía a verdadeira capitalidade, mantendo-se como a caixa de ressonância do Brasil (Motta, 2000).

Carlos Lacerda era político e jornalista, e exerceu ambos os papéis de forma polêmica. Sua atuação política foi marcada por um forte antigetulismo, herdado de seus anos de militância pelo Partido Comunista, de onde seria afastado em 1939, quando desenvolveria também acentuado sentimento anticomunista. Fundador da Tribuna da Imprensa em 1949, utilizaria o jornal como plataforma de onde lançava suas opiniões contundentes, que algumas vezes tiveram efei- 
to drástico: o suicídio de Vargas (1954) e a renúncia de Jânio Quadros (1961), por exemplo.

Assim, é fácil compreender que um movimento artístico identificado com as esquerdas, e representando o Rio pelo viés da exclusão social, se apresentasse como uma ameaça a seu governo. Como indício da campanha de Lacerda contra o Cinema Novo, pode-se citar um trecho de Estética da fome, artigo/manifesto de Glauber Rocha publicado em 1965: "Esse miserabilismo do Cinema Novo opõe-se ao digestivo, preconizado pelo crítico-mor da Guanabara, Carlos Lacerda: filmes de gente rica, em casas bonitas, andando em automóveis de luxo" (Rocha, 2004: 65). A resposta do cineasta faz pressupor alguma provocação lacerdista que defendesse para o Rio um cinema mais "elitista".

No entanto, o embate não foi muito pragmático. Apesar de ter criado, no final de 1963, uma Comissão de Apoio à Indústria Cinematográfica (CAIC) vinculada ao Banco do Estado da Guanabara e à Secretaria de Turismo - que poderia ter servido para implementar uma política cultural voltada para o fomento de produções que estivessem de acordo com sua visão de cidade, isso não ocorreu. $\mathrm{O}$ aparente desinteresse do governador e do secretário de Turismo em participar da escolha dos projetos e a autonomia dada aos secretários-executivos, favoráveis ao Cinema Novo, acabou por ajudar o movimento (Carvalho, s/d.). Outra leitura pode ser encontrada em Alexandre Figueirôa (2004), que defende a hipótese de que tal postura fosse parte dos investimentos de Lacerda em sua futura campanha para a presidência. ${ }^{1}$ Segundo o autor, Lacerda desejaria apresentar-se como defensor das liberdades democráticas e sabia que a notoriedade do movimento no pós-1964 exigia uma revisão de seu posicionamento.

\section{A narrativa de uma grande cidade}

A abordagem do filme será feita a partir do reconhecimento e decodificação de sua narrativa, que, apreendida em conjunto com a diegese, possibilita ler a representação que a obra realiza do Rio. ${ }^{2}$ Assim, "não se trata de fazer a obra confessar um sentido 'inconsciente' que ela esconderia, [mas] de examinar simplesmente como o sentido é produzido" (Leutrat, 1995: 31). O trabalho consiste, portanto, no enfrentamento do específico fílmico (Kornis, 1992) para, a partir daí, produzir conhecimento. Ao mesmo tempo, o filme é compreendido como um dos agentes do contexto descrito nos parágrafos acima, sendo a representação encarada como fruto da intencionalidade de atores sociais. $\mathrm{O}$ "embate" a que se refere $\mathrm{o}$ título deste artigo se dá pela disputa de sentidos em torno da capitalidade, levada a cabo principalmente através da representação crítica de dois espaços urbanos privilegiados pelo governo Lacerda: as favelas e o Aterro do Flamengo. 
Partirei da apresentação de uma sinopse detalhada da obra, para em seguida realizar a análise de trechos selecionados por sua centralidade quanto aos aspectos que pretendo abordar. Na diegese, Luzia (Anecy Rocha) viaja de Pernambuco para o Rio em busca de Jasão (Leonardo Vilar), seu noivo, que migrara alguns anos antes. Por ter se tornado matador de aluguel e estar foragido, Jasão rejeita a continuação do romance para protegê-la. Apesar disso, ela decide buscar seu lugar na metrópole, contando com a ajuda de Calunga (Antônio Pitanga) e Inácio (Joel Barcelos), também migrantes, conforme indica o subtítulo em forma de cordel: As aventuras e desventuras de Luzia e seus três amigos chegados de longe.

Luzia consegue um emprego como copeira em um escritório e se mantém fiel a Jasão, apesar de, às vezes, quase ceder ao interesse erótico e afetivo demonstrado por Calunga e Inácio. Inácio é um pedreiro que mora nos canteiros de obra em que trabalha, enquanto Calunga não tem ocupação definida, assemelhando-se à figura do "malandro carioca", embora baiano. É por meio de ambos que Luzia conhece a cidade, circulando por diversos lugares do Centro e das Zonas Sul, Oeste e Norte (em que fica a Mangueira, onde Jasão mora). Nos diálogos, as vantagens de voltar para o sertão e os perigos de permanecer na cidade são, a todo o tempo, lembrados a ela por Inácio e Calunga, respectivamente. Enfim, Luzia se mostra resoluta quanto à ideia de permanecer no Rio ao lado de seu noivo, que, àquela altura, já decidira abandonar os crimes para reconstruir a vida ao lado dela. Contudo, ao final, ambos são mortos em uma operação policial para capturar Jasão no Centro da cidade, durante o Carnaval.

Passo agora à análise de alguns trechos da sequência de abertura que, em um filme urbano, pode ser um elemento importante para definir a relação que a obra estabelece com a cidade (Vienne, 2005). A primeira imagem - em p\&b, como todo o filme - a surgir na tela é um plano geral da Baía de Guanabara e do Pão de Açúcar, com o ator Antônio Pitanga entrando no quadro de baixo para cima. Ele olha diretamente para a câmera/espectador e diz: "Quem quer que tenha visto o Rio de Janeiro não poderá recusar a sua admiração para as grandes e belas coisas que se oferecem às nossas vistas”. Como seu personagem, Calunga, ainda não foi apresentado, parece se tratar de um aposto na narrativa, uma estrutura diferenciada que me leva a crer que a sequência de abertura irá atuar como um prólogo.

Recurso originado na tragédia grega, quando um ator entrava em cena antes do coro e da orquestra para anunciar o tema da peça (Moisés, 2002), o prólogo se adequa a uma obra que dialoga com o orfismo - a descida aos infernos, no mito de Orfeu (Coelho, 2008). Ao mesmo tempo, serve para forçar a afinidade com as narrativas de cordel, evidenciada pela mobilização do modo fabulizante de ver, de acordo com tipologia proposta por Roger Odin (2005). Afinal, segundo o 
autor, essa forma de leitura sugere justamente que o filme forneça uma aprendizagem ao espectador.

Odin explicita que esse modo de ver é construído sobre um processo que separa um narrador real de um enunciador fictício, sendo este o responsável pela narrativa. O personagem que discursa, conduzindo ao enunciado da moral, subordina o enunciador fictício, pois "a narrativa deve apenas ilustrar o discurso" (Odin, 2005: 35). Pitanga, portanto, tem duplo papel na obra de Diegues: é o narrador real, uma espécie de corifeu, e Calunga.

A Baía de Guanabara e o Pão de Açúcar, por sua vez, são clichês cinematográficos que dialogam com o imaginário social da cidade. À época, era comum que o Rio fosse representado no cinema brasileiro e estrangeiro principalmente através de seus ícones urbanos intimamente vinculados à monumentalidade da natureza (baía, montanhas, praias). Tal processo, em associação com dadas situações diegéticas comumente repetidas, reforçou a imagem da cidade como território livre das amarras da civilização (Amancio, 2000; Freire-Medeiros, 2005). No filme, em consonância com essa vertente, surge sobre a tela uma descrição laudatória da Baía de Guanabara, de autoria do Padre Simão Vasconcelos (1663). No som extradiegético, a locução de um jogo de futebol, o que aparentemente não tem nada a ver com a imagem.

A sequência continua, com Pitanga destilando afirmações sobre o Rio, louvado como "a mais fértil e viçosa terra que há no Brasil", um verdadeiro "paraíso terrestre". Embora a autoria não seja assumida, é possível reconhecer trechos de relatos dos viajantes Pero de Magalhães Gândavo (1576) e Évariste Parny (1826). De forma irônica, nesse momento, a construção visual dos quadros abarca, por trás do ator, não mais a natureza deslumbrante, mas uma massa compacta de edifícios, sem nenhum índice de reconhecimento topográfico.

Mais adiante, através de um corte, o ator "desce" para a materialidade contemporânea da "grande cidade" que, do alto do passado - e dos establishing shots $^{3}$ - ainda poderia ser vista como um paraíso. Essa nova sequência exibe Pitanga circulando pelas ruas, fazendo uma série de perguntas à população carioca: a que horas dormem, comem, amam. A montagem é fragmentada, havendo quase sempre um corte entre uma questão e outra. Depois das perguntas, enquadra-se $\mathrm{o}$ ator num plano geral caminhando pelo meio de uma rua movimentada $\mathrm{e}$ lendo em voz alta o conteúdo de uma folha de papel ofício. O texto descreve a rotina de um personagem urbano qualquer, listando suas atividades e medindo o tempo gasto em cada uma delas. Por fim, ele conclui que "se essa pessoa morrer aos 50 anos, na verdade viveu apenas seis, pois o resto consumiu em coisas desagradáveis ou inúteis", como trabalhar e ficar retido no trânsito. Retomando algumas das perguntas feitas aos transeuntes anteriormente, $o$ ator olha para a câmera e conclui: "O que que estão fazendo no cinema?". 
Deve-se atentar para a proposta de romper com os códigos narrativos canonizados pelo cinema hollywoodiano. Aqui, a regra com que se rompe é a de que o ator nunca deve interpelar diretamente o espectador, em respeito ao jogo de faz de conta realista, que pretende apresentar uma narrativa objetiva com um narrador discreto, quase invisível (Xavier, 2007). Na contramão dessa proposta, Pitanga assume uma postura brechtiana, rompendo a "quarta parede" e interpelando a plateia, bem como os transeuntes nas ruas da cidade - o que reforça sua dupla atuação no filme. Ainda, é através dessa interlocução direta que ele desfia os textos laudatórios sobre a cidade, ato complementado visualmente pelo ícone urbano que é o Pão de Açúcar. Ao mesmo tempo, essa imagem - fortemente associada à capitalidade e à ideia de "paraíso tropical" - é contraposta, pelo corte descrito, à multidão anônima e sorumbática, vagando por ruas que não fazem a mais remota evocação da ideia de paraíso. Inclusive, o plano de abertura é encerrado com Luzia, a protagonista, caminhando pelas imediações da favela da Mangueira, recém-chegada do sertão. No som extradiegético, uma música instrumental confere grandiloquência ao plano geral que exibe a moça, em dimensões diminutas, vagando pelas ruas da grande cidade. ${ }^{4}$

Cabe refletir um pouco mais sobre os elementos referentes à capitalidade que estão presentes nessa abertura. Concordo com a defesa de que o Rio, por conta da monumentalidade de sua natureza, já possuísse capitalidade - no sentido de uma capacidade de representar a América portuguesa - quando se tornou capital (Rodrigues, 2002). Contudo, acredito ser forçoso ir além: afinal, o exercício do papel de cidade-capital - "foco da civilização, núcleo da modernidade, teatro do poder e lugar de memória" (Motta, 2004:9) - é um dos fatores que ajudam a delinear o imaginário urbano carioca.

Como a complexidade desse processo não caberia aqui, me atenho brevemente sobre dois pontos de inflexão. O primeiro, a construção da ideia de síntese da nação realizada pelo poder federal através das reformas do prefeito Pereira Passos no início do século XX (Freire, 2000). A partir de então, a monumentalidade da natureza carioca, apesar de não ter sido "domada", passaria a conviver com a ideia de modernidade, sendo ambas tomadas como índices da cultura nacional. Assim, o Rio poderia representar o Brasil porque funcionava como o "cadinho" em que natureza, cultura e modernidade eram processadas.

O segundo momento ocorreu durante a Era Vargas, sendo uma das estratégias para fazer frente ao excessivo poder conquistado por São Paulo ao longo das primeiras décadas do século XX. Depois de conquistar o poder em 1930, Getúlio se esforçou para reverter uma campanha difamatória iniciada na década anterior, segundo a qual os cariocas seriam vistos como lascivos, preguiçosos e indolentes em comparação com os paulistas, "bandeirantes empreendedores" (Motta, 1992). Era uma forma de desautorizar a capitalidade do Rio, alçando São Paulo ao posto de paradigma do Brasil. 
Através de elaboradas políticas culturais que o autoritarismo facilitava, e que muitas vezes se aproximavam de leituras realizadas pelos modernistas - inclusive os paulistas -, o governo de Getúlio reforçaria, como características nacionais, as especificidades cariocas (Oliveira, 2000). Entre estas, mais uma vez estava a paisagem natural, mas figuravam também elementos típicos da cultura popular, como o futebol. Embora não tenha sido adotado apenas por cariocas, o processo de abrasileiramento desse esporte de origem inglesa passou, via modernismo, pela associação à ginga de sambistas e capoeiras (Hollanda, 2004) - estes, sim, marcantes na paisagem cultural do Rio. Lembro que o futebol está presente, mesmo que de modo sutil, na sequência de abertura do filme.

A favela seria a outra protagonista desse processo. Embora no início do século ela fosse um fenômeno incipiente - de certa forma deflagrado pelas reformas Passos -, não tardaria a ganhar relevo. Ao longo das décadas de 1940 e 1950, duas tendências surgiram na forma de abordá-la: por um lado, como "um problema social, estético, higiênico, urbanístico e policial", por outro, a partir de "uma visão que enaltecia a cultura musical e artística do favelado e a sua luta diária pela sobrevivência" (Perez, 2007: 251). A Era Vargas pode ser identificada com ambas: ao mesmo tempo em que as favelas passaram a ser controladas, e muitas delas destruídas, elementos tradicionalmente associados a elas - como o samba, o malandro (“domado" e livre de toda periculosidade) e a mulata - se converteram em ícones de nacionalidade (Abreu, 2000). Assim, não surpreende que na abertura do filme a Mangueira figure ao lado do Pão de Açúcar, ambos identificados com aspectos diversos da capitalidade.

\section{Na cidade, o sertão é a favela}

No prosseguimento da análise de $A$ grande cidade, percebo que as propostas apresentadas na abertura do filme são cumpridas ao longo da narrativa. Esta procura demonstrar a tese de que o destino do migrante na cidade é trágico. Em diversos momentos, os personagens nordestinos se referem ao sertão como um inferno do qual tentaram sair. Mesmo Inácio, que deseja retornar, acredita que o sertão seja um "inferno" mais adequado à sua sina. Por outro lado, a cidade também aparece como um espaço infernal nas falas de todos os personagens. Por exemplo, logo após a abertura, Calunga solicita que Luzia respire fundo, dizendo: "bota o inferno pra dentro de você". Por conseguinte, a equação entre sertão, inferno e cidade está sempre presente, embora tenha conotações diferentes para cada personagem. Todavia, essa equação é contrabalançada por dois elementos: a lógica dos pertencimentos, que explica o sertão ser melhor do que a perda de referenciais deflagrada pela modernidade urbana; e a representação da favela como um "refúgio" no inferno da cidade. 
Na década de 1960, quando Lacerda chega ao poder e o Cinema Novo começa a surgir, a dicotomia apresentada anteriormente quanto ao modo de apreensão da favela ainda estava vigente. Embora seja arriscado vincular partidos e ideologias políticas a tais tendências, pode-se apontar aproximações. As esquerdas, muitas vezes como parte de uma estratégia de conscientização, tenderam a se relacionar de forma empática com os favelados, procurando se inserir na lógica sociocultural das comunidades, privilegiando a proposta de urbanização das favelas, em vez de sua erradicação (Guimarães, 2009). O Cinema Novo alinhava-se, de forma geral, com esse lado.

Já o governo Lacerda seguia a primeira tendência, apresentando projetos de remoção de favelas e transferência dos moradores para conjuntos habitacionais construídos ao longo da Avenida Brasil. Embora tais ações tenham sido responsáveis pela alcunha pejorativa de "removedor de favelados" e pela acusação de vínculos escusos com o mercado imobiliário, é importante levar em conta que a proposta era alojar os ex-favelados perto dos novos distritos industriais da Zona Oeste, que deveriam ser desenvolvidos através de incentivos fiscais e criação de infraestrutura (Perez, 2007).

No filme, mesmo que a chegada de Luzia - vinda do sertão - seja mostrada como um processo duro, a maneira como a favela da Mangueira aparece na narrativa poderia, descontada certa ambiguidade, ser considerada benevolente. Já no início, a favela é exibida em plano aberto, enquanto Luzia olha para ela sem demonstrar qualquer rejeição. Mais tarde, em uma das conversas que mantém com Calunga, ela pergunta se ele "botou casa em Mangueira", ao que o outro responde: "Deus me livre! Já viu uma favela?". Embora o tom de indignação revele seu desprezo, em seguida Calunga relativiza tal opinião: "Em Mangueira tenho uns amigos lá na Escola...”. Um indício de que, apesar da falta de infraestrutura, a favela pode ser reconhecida como um espaço seguro e propício à constituição de amizades.

Esse indício é confirmado algumas cenas adiante, quando Luzia chega, de maleta na mão, à quadra da Escola de Samba Estação Primeira de Mangueira. Takes de passistas sambando alegremente, ao som de $O$ descobrimento do Brasil (Geraldo Babão), samba-enredo do Salgueiro de 1962. Entre eles, Calunga, demonstrando familiaridade e descontração. Em plano aberto, Luzia cruza o quadro da direita para a esquerda, enquanto algumas pessoas observam a câmera. Calunga se aproxima dela, oferecendo ajuda mais uma vez. Ela diz que procura pelo noivo e começa a descrevê-lo, mas logo para quando o avista recostado num muro. $\mathrm{O}$ samba é substituído por uma música extradiegética, com tonalidade sertaneja. Apesar de fazer menção de ir a seu encontro, o homem estanca no meio do caminho e desiste. Ato contínuo, o espanto de Calunga revela o motivo da fuga: o noivo é um matador de aluguel, apelidado Vaqueiro. 
Luzia sai correndo e um corte leva a uma longa sequência em uma praça, em que ela desabafa com Calunga sobre a decepção amorosa e o medo da cidade. A sequência reforça os laços entre os dois personagens, deixando claras as intenções de Calunga de apoiar Luzia em seu processo de adaptação. Ainda que ele não seja um morador da Mangueira, acredito que a sugestão de seu pertencimento à rede de relacionamentos da favela permita estender sua atuação aos habitantes do lugar. O tom documental da sequência na Quadra, denunciado pelas pessoas que encaram a câmera com curiosidade - evidenciando não serem figurantes profissionais, mas pessoas que realmente frequentavam aquele espaço -, reforça a intenção narrativa de mostrar os liames entre a ficção e a realidade. Logo, no lugar de Calunga, cuidadoso e solidário, poderia estar qualquer um dos moradores "reais" da favela. Por conseguinte, é ali que Luzia reencontra uma rede de apoio e cooperação que perdera ao sair do sertão.

Porém, se até aqui a representação positiva da favela é apenas sugerida, a forma como Jasão/Vaqueiro se relaciona com esse espaço ajuda a explicitá-la. Depois de tentar fugir de Luzia, ele marca um encontro, usando Calunga como mediador. Em frente a um botequim próximo à Mangueira, ele diz que mora "ali, no morro", fazendo um gesto com a cabeça. O "morro" não é mostrado, mas Luzia comenta que é bonito, sem tirar os olhos de Jasão. Aqui, se por um lado ela parece não concordar com a opinião de Calunga sobre a aparência da favela, por outro poderia apenas estar se referindo à beleza de Jasão, pois seu olhar permanece sobre ele. Contudo, a expressão do noivo é de fato benevolente, ainda mais se for levado em consideração que ele saiu do "inferno" do sertão para construir uma vida melhor para Luzia. Penso que, caso o personagem não considerasse a favela um lugar adequado a esse fim, o ator deveria acrescentar algum constrangimento à elocução, o que não faz.

Mais adiante, quando Jasão aparece cometendo assassinatos, se confirma a separação entre a cidade e a favela. Afinal, mesmo que o matador more na Mangueira, não é ali que seus crimes são cometidos, sendo um deles, inclusive, alocado em frente a um cartão-postal, novamente o Pão de Açúcar. Desse modo, um personagem que representa a um só tempo a violência sertaneja e urbana mostra-se dócil e inofensivo quando se encontra na favela, que é destacada, portanto, do inferno urbano.

Embora sejam muitos os fatores que influenciam tal representação da favela - como as já comentadas afiliações políticas dos cineastas - acredito que a interlocução do Cinema Novo com o modernismo seja uma chave de leitura fundamental, mesmo que mais associada pela historiografia à representação do sertão (Debs, 2004; Xavier, 2001). Geralmente vinculada à Semana de Arte Moderna de 1922, essa relação deve ser mais bem especificada, uma vez que o modernismo da Semana - calcado em ações iconoclastas e no entusiasmo pela modernidade urbana - é diferente daquele com que o Cinema Novo dialoga. 
De acordo com a proposição de Eduardo Jardim de Moraes (1998), defendo que o maior ponto de inflexão do movimento seja o Manifesto Pau-Brasil, em 1924. É a partir desse momento - certamente em São Paulo, mas não só - que se inicia a gestação de um modernismo brasileiro, e não mais de um "modernismo no Brasil". Diferentemente das vanguardas europeias, que realizaram uma ruptura com a história (Schorske, 1990; Gay, 2009), quebrando os vínculos com as tradições e se aventurando no universo abstracionista, aqui a ideia de ruptura seria parcial (Fabris, 2002). Nessa empreitada, o rompimento estético e a pesquisa histórica estavam aliados, gerando, nos termos de Ronaldo Brito (1983), uma modernidade paradoxal.

Nesse âmbito, além do sertão, o carnaval e a favela cumpriram função central no desenvolvimento de uma representação da brasilidade, como ocorre no Manifesto Pau-Brasil: "O carnaval. O Sertão e a Favela. Pau-Brasil. Bárbaro e nosso" (Andrade, 2003, grifos nossos). Reforçam-se, assim, os laços entre esses dois espaços, fazendo a favela surgir como uma "filial" do sertão no seio da cidade, ambos detentores de algum aspecto, ainda não claro, representativo do nacional. Por certo, tal leitura passa pela "autenticidade" dos espaços onde a modernidade se faz ausente. É digno de nota que a década de 1920 seja um marco para a generalização do termo "favela" para se referir a um conjunto de moradias localizadas no alto dos morros e ocupadas por moradores de baixa renda. Essa generalização, pensada concomitantemente ao Manifesto, pode ser lida como a emergência da favela como ideia. Mais do que dado, o que ela já era desde o início do século, tornava-se fato estético e intelectual (Cavalcanti, mimeo).

Assim, mediada pela interlocução com o imaginário consolidado pelo modernismo, tal apreensão da favela permite esclarecer a relação dialógica do filme como o governo de Lacerda, marcada pelo tom crítico, pois calcada no contraste com suas ações. Tal "conversa" pode ser também encontrada na forma como a narrativa representa o Aterro e o Parque do Flamengo, outro ponto de destaque desse governo.

\section{O Aterro: modernismo e modernização}

Inaugurado em 1965, ano de comemoração dos 400 anos do Rio, o Aterro era para o governo de Lacerda, ao mesmo tempo, uma obra urbanística necessária ao plano viário da cidade e uma construção simbólica. Através dele Lacerda firmaria, "ao mesmo tempo, uma autoimagem e uma imagem para o estado que governava" (Motta, 2009: 131). Afinal, a obra foi apresentada como o coroamento da história do Rio, que começava por sua fundação, no Morro do Castelo, e desembocava no Aterro, modernista, ousado, apontando para o futuro (Motta, 
2000). Lacerda fazia desse investimento, portanto, a sua resposta a Brasília, trazendo para a Belacap (Rio) o modernismo arquitetônico que tanto fascinava na Novacap (Brasília). Assim, a obra se converteria no "espelho carioca do plano para a nova capital, [representando] a vitória total do pensamento urbanista moderno ortodoxo" (Cavalcanti, 2001: 54). Ainda, funcionava como alavanca para a candidatura do governador à presidência do país.

Realizado com material obtido do desmonte do Morro de Santo Antônio (ironicamente só possível graças à remoção de uma favela no governo anterior), o Aterro ocupa $1.200 \mathrm{~km}^{2}$ ganhos ao mar, do Centro a Botafogo. Só viria a abrigar também o Parque do Flamengo - no lugar de quatro de suas oito pistas de carro - por conta de Lota de Macedo Soares, que insistiu nas vantagens do projeto. Livre pensadora, socialite e amiga íntima de Carlos Lacerda, Lota foi nomeada - sem ônus para o Estado (Nogueira, 2011) - para comandar uma Comissão de Criação do Parque, ligada à Superintendência de Urbanização e Saneamento (Sursan) e à Secretaria de Viação.

Sua escolha por parte de Lacerda não se devia, apesar das aparências, a um jogo de troca de favores. Arquiteta amadora, Lota era entusiasta do modernismo e convocou profissionais vinculados a esse ideário para formar a Comissão, como o arquiteto e urbanista Affonso Eduardo Reidy e o paisagista Roberto Burle Marx. Apesar das críticas por seu valor faraônico, o Parque rendeu o resultado esperado. Como Lota escreveu a Lacerda, “Água e escola são fatos naturais que todo governo tem obrigação de fazer. A única coisa de que vão lembrar é que você fez o Parque do Flamengo" (Nogueira, 2011: 134).

Em $A$ grande cidade, a primeira vez em que o Aterro é mobilizado se dá em uma sequência em que Luzia e Inácio passeiam pelo Monumento aos Mortos da II Guerra Mundial (Monumento aos Pracinhas) ao som extradiegético de um $i \hat{e}-i \hat{e}-i \hat{e}$ de Roberto Carlos. Mais adiante, ouve-se Maria Bethânia cantar uma composição de João de Barro, Anda Luzia. Luzia anda entre estudantes que visitam o lugar, rindo e se divertindo, enquanto a câmera gira em torno dela.

Em seguida, ela contempla a sua imagem refletida numa das paredes de mármore preto do monumento, em que a Baía de Guanabara também está visível. No som extradiegético, Maria Bethânia ainda canta: "A vida dura só um dia, Luzia/ E não se leva nada desse mundo". Luzia se encosta à parede e pergunta para Inácio se ele seria capaz de "dormir com ela". A câmera, que a enquadrava num plano médio, aproxima-se, oscilando levemente. Corta para um close dele: "Hein!?". A câmera volta a buscar o rosto de Luzia e ela responde "Nada", olhando para outro lado e sorrindo com um toque de malícia. Um conjunto de cinco caças sobrevoa o Aterro.

Não se pode dizer que essa sequência seja de todo inocente. Afinal, é fechada com cinco caças, imagem imediatamente associada às Forças Armadas, 


\section{Carlos Eduardo Pinto}

opção no mínimo capciosa num filme realizado durante uma ditadura em que militares eram atores de destaque. Contudo, a representação desse espaço da cidade está próxima de um dos usos que se encontravam na base de sua concepção: o lazer. É digno de nota o fato de as cenas não exibirem, em nenhum momento, enquadramentos em plano geral do monumento. Esse formato, que permitiria a sua contemplação - função primeira de sua existência -, é recusado em nome de uma focalização mais intimista, que privilegia as expressões de prazer dos personagens.

É interessante pensar que os autores do projeto de 1956, Marcos Konder e Hélio Ribas, defendiam como um dos diferenciais desse locus de memória justamente a possibilidade de ser fruído como espaço de diversão (Mauad e Nunes, 1999). Assim, a narrativa e a diegese assumem essa proposta, fazendo um uso convencional do espaço.

O Aterro será novamente agenciado pelo filme já na sequência final, depois do assassinato de Jasão e Luzia durante o Carnaval. Calunga, que foi testemunha do crime, é observado pelos policiais, que por seu lado o apontam como um "contato" inofensivo do Vaqueiro. Ele, que não consegue ouvir o que os policiais falam, se assusta e começa a correr pela cidade. A câmera o acompanha em uma série de travellings, ouvindo-se no som extradiegético um coro cantar a "nossa grande cidade, cidade do amor", parte da letra de $A$ grande cidade, samba composto por Zé Kéti para ser o tema do filme. Interessante observar que tal letra tenha o mesmo tom ufanista de todos os sambas que foram compostos para os desfiles das escolas de 1965, quando, impelidos pelo governo a tratar do IV Centenário, os sambistas ficaram restritos aos temas históricos da cidade. Nessas letras, as favelas não surgem, nem mesmo em uma versão idealizada. Há referências ao nascimento do samba e elogios à miscigenação racial, num estilo que rescende ao Estado Novo, ${ }^{5}$ mas nenhuma contextualização desses processos que os localizem nas favelas.

A sequência dá prosseguimento à corrida de Calunga pelas ruas do Centro até que, através de uma elipse, ele chega ao Aterro. Em um plano geral muito aberto, o ator é mostrado de corpo inteiro, um pouco à direita do quadro, no meio de uma paisagem limpa, com algumas árvores recém-plantadas. Ele caminha em direção ao primeiro plano, parando no centro do quadro e, como na sequência de abertura, fala olhando diretamente para a câmera. Diz que a valentia não serviu de nada para eles - Luzia e Jasão - e que, em vez de faca, tiro, amor, traição, ele, que não fez nenhum ato valente, tem riso e lágrimas e o manto da memória. "A guerra é grande e tá todo mundo nela. Eu não!!!”, diz num tom grandiloquente, abrindo os braços e olhando para o céu. Em seguida, corre em direção à câmera $\mathrm{e}$ logo desvia, sendo acompanhado por uma panorâmica da direita para a esquerda. 
Calunga salta enfim para dentro de um anfiteatro e começa a desenvolver alguns movimentos que mimetizam agonia, o que, realizado numa arena, formato de alguns teatros gregos na Antiguidade, reforça a hipótese da relação do filme com a tragédia (Coelho, 2008). Sobreposto à cena, um texto assinado por De la Salle: "Todos os viajantes sentem prazer em celebrar a beleza da baía do Rio de Janeiro. E, no entretanto, quem pode gozar desse magnífico espetáculo acha-o muito acima de tudo o que os livros lhe ensinaram" (Leitão, 1934). ${ }^{6}$ Os créditos finais são exibidos, ao som da mesma música instrumental da abertura. A imagem de Calunga na arena permanece, sendo ainda possível ouvir alguns gritos que acompanham movimentos mais bruscos. Ao emitir um desses gritos, contorcendo-se muito, ele sai da arena e começa a correr pelo Aterro. A câmera inicia um movimento ascendente, mostrando o desenho geométrico - tipicamente modernista-dos jardins e, ao fundo, o Hotel Glória. A palavra Fim surge na tela.

Considero bastante significativa a escolha do Aterro como lugar de encenação da sequência de encerramento, cuja intencionalidade pode ser sustentada pela opção nada óbvia em termos diegéticos. Da Praça XV ao Aterro, na altura da Glória, existe uma distância substancial e nada que justifique a opção de Calunga em seguir por essa direção (a não ser o fato de desejar escapar aos espaços mais óbvios, por conta da perseguição policial). Junto a isso, se dá a retomada do estilo brechtiano, já presente na abertura, o que faz com que o "cenário" deixe de ser uma escolha naturalista, inserida na diegese, e passe a ser encarado mais como um segundo discurso paralelo às falas. Como visto, estas se referem ao assassinato de dois migrantes nordestinos favelados.

Logo, a partir da relação dos cinemanovistas com Lacerda, seria plausível pensar que, contra a Teoria da Modernização, que via nas favelas um mal a ser erradicado e nas reformas urbanas um ganho para toda a sociedade, a narrativa apresenta a modernização como um dos palcos da tragédia dos favelados. A perspectiva a partir da qual o Aterro foi filmado no final, com auxílio de uma grua, reforça tal leitura. $\mathrm{O}$ jardim, com árvores recém-plantadas, apresenta-se como um imenso vazio, com a luz estourada num branco intenso na fotografia em $\mathrm{p} \& \mathrm{~b}$, o que ajuda mais uma vez a aproximar o sertão da cidade. Assim, o que era símbolo da modernidade para o governo, ao mimetizar o sertão se converte em símbolo de subdesenvolvimento. Em uma narrativa em que essa aproximação já foi tentada de diversas outras formas, tal leitura pode ser validada. Ainda, as imagens indicam a dimensão ínfima do drama que Calunga encena diante da grande escala da cidade.

Contudo, menos que uma crítica direta, o que se percebe é uma aproximação dúbia. Afinal, algumas propostas que estão na base da concepção do Aterro são aceitas e incorporadas pela narrativa, como mais claramente na sequência do Monumento aos Pracinhas. De fato, a aproximação do Cinema Novo com o modernismo arquitetônico era marcada por tensões. Por um lado, o mesmo fas- 
cínio pela inovação da linguagem que pautava a interlocução com outras manifestações modernistas. Por outro, a associação entre o universo modernista e os processos de modernização, ameaçadores à essência nacional que pretendiam proteger. É esta última faceta que coloca os cinemanovistas mais diretamente em diálogo com o governo Lacerda, em um embate por formas de representação da cidade, senão opostas, ao menos mutuamente críticas.

\section{Considerações finais}

Ao fim da análise de alguns aspectos narrativos e diegéticos de $A$ grande cidade, é possível perceber alguns pontos de relação entre o contexto carioca e o Cinema Novo. Com pretensões a descobrir e preservar a essência da brasilidade, os cinemanovistas encontram na ex-capital - ainda detentora de capitalidade um locus mais apropriado a um debate que opõe "pureza" e "modernização". Por outro lado, o contexto de criação da obra - tendo o embate entre os cinemanovistas e Lacerda como um de seus vetores - aponta para a presença de uma disputa simbólica pela criação de uma dada representação da cidade.

Embora o sertão também fosse - aos olhos dos cineastas - o lugar da brasilidade, ele não possuía os mesmos elementos que poderiam ser discutidos na cidade. O Rio, por conta da capitalidade, poderia representar, de forma mais eficiente, a tensão entre nacionalidade e modernização, um tema caro ao movimento. Especificamente no campo diegético, o papel tradicionalmente reservado ao sertão é desempenhado pela favela, enquanto a modernização encontra no recém-inaugurado Aterro do Flamengo o seu ícone mais eficiente. Assim, a crítica ao governo se dá através da mobilização da linguagem cinematográfica, que possibilita se apropriar de elementos marcantes de seu governo, fazendo uma representação diferenciada da que ele propunha.

Notas

1. Tal campanha não viria a se realizar, por conta do cancelamento das eleições diretas para presidente pelo Ato Institucional (AI-2) em 1965.
2. A diegese é o universo dos personagens. Ela deve ser diferenciada da narrativa, que é a forma como a história é narrada. A diegese está contida no argumento do 
filme, enquanto a narrativa se realiza com o filme, englobando fotografia, movimentos de câmera, trilha sonora, atuação, direção de arte e outros. O termo diegese pode se desdobrar em extradiegético, utilizado para se referir a elementos que fazem parte da narrativa, mas não da diegese, como, por exemplo, uma canção ouvida pelos espectadores, mas não pelos personagens.

3. Planos aéreos de uma paisagem cuja função principal é localizar a ação. Nesse caso, as tomadas da Baía da Guanabara e do Pão de Açúcar são establishing shots que remetem a imagens plenamente divulgadas da cidade, vulgarmente referidas como "imagens de cartão postal".

4. Os créditos não apresentam uma relação precisa entre os trechos musicais e seus autores. Informa-se apenas que há excertos

\section{Referências bibliográficas}

ABREU, Regina. A capital contaminada: a construção da identidade nacional pela negação do "espírito carioca". In: LOPES, Antônio Herculano (org). Entre Europa e África: a invenção do carioca. Rio de Janeiro: Fundação Casa de Rui Barbosa/Topbooks, 2000.

AMANCIO, Tunico. O Brasil dos gringos: imagens no cinema. Niterói/ Rio de Janeiro: Intertexto, 2000.

ANDRADE, Oswald de. Manifesto PauBrasil. In: CAIXA Modernista. São Paulo: Edusp/ Ed. UFMG/ Imprensa Oficial, 2003. Edição fac-similar.

BERNARDET, Jean-Claude; GALVÃO, Maria Rita. O nacional e o popular na cultura musicais de Hekel Tavares, Villa-Lobos e Ernesto Nazaré.

5. Por exemplo, o samba-enredo da Portela, História e tradição do Rio quatrocentão (Nelson de Andrade), faz referência ao samba de forma indireta, com o verso "Rio antigo das batucadas". Mais adiante, a miscigenação também é cantada: "Hoje, no século XX, do caldeamento de raças/ Surgiu com requinte e graça/ No mundo aristocrata/ Consagrada beleza exuberante da mulata". Disponível em: http://www. gresportela.com.br/?posttype $=$ outroscar navais $\& \mathrm{p}=441$ [consultado em 3/2/2012].

6. O trecho final apresenta dificuldades à leitura na versão em DVD. Encontrei o complemento da citação em: http://www. brasiliana.com.br/obras/visitantes-do-pri meiro-imperio/pagina/56 [consultado em 3/11/2012].

brasileira - Cinema. São Paulo: Brasiliense, 1983.

BRITO, Ronaldo. A semana de 22: o trauma do moderno. In: V. A. Sete ensaios sobre o modernismo. Rio de Janeiro: Funarte, 1983.

CARVALHO, Júlia Machado; PEREIRA, Miguel Serpa. A presença do Estado no cinema: o caso da CAIC. Relatório de pesquisa apresentado ao CNPQ. s/d.

CAVALCANTI, Lauro. Quando o Brasilera moderno. Guia de Arquitetura (1928-1960). Rio de Janeiro: Aeroplano, 2001. 
CAVALCANTI, Mariana. Aesthetic representations of Rio de Faneiro's favelas (19241968). (mimeo)

COELHO, Maria Cecília de Miranda N. Revendo $A$ grande cidade, de Cacá Diegues: o orfismo às avessas da periferia. In: HAMBURGUER, Esther et al (org.). Estudos de Cinema - Socine, IX. São Paulo: Annablume; Fapesp; Socine, 2008.

DAHL, Gustavo et al. Vitória do Cinema Novo (debate). Revista Civilização Brasileira, n. 2, 1965.

DEBS, Sylvie. Cinema e literatura no Brasil: os mitos do sertão: emergência de uma identidade nacional. Belo Horizonte: C/Arte editora, 2010.

FABRIS, Annateresa. Figuras do moderno (possível). In: SCHWARTZ, Jorge (org). Da antropofagia a Brasília: Brasil 1920-1950. São Paulo: Cosac e Naify/FAAP - Fundação Armando Álvares Penteado, 2002.

FIGUEIRÔA, Alexandre. Cinema Novo: $a$ onda do jovem cinema e sua recepção na França. Campinas: Papirus, 2004.

FREIRE, Américo. Uma capital para a República: poder federal e forças políticas locais no Rio de Faneiro na virada para ao século XX. Rio de Janeiro: Revan, 2000.

FREIRE-MEDEIROS, Bianca. $O$ Rio de Faneiro que Hollywood inventou. Rio de Janeiro: Jorge Zahar Ed, 2005.

GÂNDAVO, Pero de Magalhães. 1576. História da Província de Santa Cruz... Lisboa, 2005.

GAY, Peter. Modernismo - o fascinio da heresia: de Baudelaire a Beckett e mais um pouco. São Paulo: Cia das Letras, 2009.

GUIMARÃES, Valéria Lima. OPCB caino samba: os comunistas e a cultura popular (1945-1950). Rio de Janeiro: Imprensa Oficial do Estado do Rio de Janeiro, 2009.
HOLLANDA, Bernardo Borges Buarque de. $O$ descobrimento do futebol: modernismo, regionalismo e paixão esportiva em fosé Lins do Rego. Rio de Janeiro: Edições Biblioteca Nacional, 2004.

KORNIS, Mônica Almeida. História e Cinema, um debate metodológico. Estudos Históricos, Rio de Janeiro, vol. 5, n. 10, 1992.

LEITÃO, Cândido de Melo. Visitantes do Primeiro Império. São Paulo: Cia Editora Nacional, 1934.

LEUTRAT, Jean-Louis. Uma relação de muitos andares: cinema \& história. Imagens. Cinema 100 anos, n. 5, 1995.

MAUAD, Ana Maria; NUNES, Daniela Ferreira. Discurso sobre a morte consumada: Monumento aos Pracinhas. In: KNAUSS, Paulo (coord). Cidade vaidosa: imagens urbanas do Rio de Faneiro. Rio de Janeiro: Sette Letras, 1999.

MOISÉS, Massaud. Dicionário de termos literários. São Paulo: Editora Cultrix, 2002.

MORAES, Eduardo Jardim de. Modernismo revisitado. Estudos Históricos. Rio de Janeiro, vol 1, n.2, 1988.

MOTTA, Marly Silva da. A nação faz 100 anos: a questão nacional no Centenário da independência. Rio de Janeiro: Editora FGV, 1992.

Saudades da Guanabara: o campo político da cidade do Rio de Faneiro (1960-75). Rio de Janeiro: Editora FGV, 2000.

Rio, cidade-capital. Rio de Janeiro: Jorge Zahar Ed, 2004.

Entre o Castelo e o Aterro: a identidade do Rio quatrocentão. In: CARNEIRO, Sandra de Sá; SANT'ANNA, Maria Josefina Gabriel (orgs.). Cidades, olhares, trajetórias. Rio de Janeiro: Garamond, 2009. 
NOGUEIRA. Nadia. Invenções de si em história de amor: Lota E Bishop. Rio de Janeiro: Editora Apicuri, 2011.

ODIN, Roger. A questão do público: uma abordagem semiopragmática. In: RAMOS, Fernão Pessoa (org.). Teoria contemporânea do cinema, vol. II. São Paulo: Editora Senac, 2005.

OLIVEIRA, Lúcia Lippi. Cultura urbana no Rio de Janeiro. In: FERREIRA, Marieta de Moraes (Org.) Rio de faneiro: uma cidade na história. Rio de Janeiro: FGV, 2000.

OROZ, Silvia. Carlos Diegues: os filmes que não filmei. Rio de Janeiro: Rocco, 1984.

OSORIO, Mauro. Rio nacional/Rio local: mitos e visões da crise carioca e fluminense. Rio de Janeiro: Editora Senac Rio, 2005.

PARNY, Évariste. OEurres choisies... Paris: Chez Mansut Fils, 1826.

PEREZ, Maurício Dominguez. Lacerda na Guanabara: a reconstrução do Rio de Faneiro nos anos 1960. Rio de Janeiro: Odisseia Editorial, 2007.

RAMOS, Alcides Freire. Para um estudo das representações da cidade e do campo no cinema brasileiro. Fênix - Revista de História e Estudos Culturais. Abril/maio/junho, vol. 2, ano II, n. 2, 2005.
RIDENTI, Marcelo. Em busca do povo brasileiro. Rio de Janeiro/São Paulo: Editora Record, 2000.

ROCHA, Glauber. Revolução do Cinema Novo. São Paulo: Cosac e Naify, 2004.

RODRIGUES, Antonio Edmilson. Em algum lugar do passado. In: AZEVEDO, André Nunes de (org.). Rio de Faneiro - capitale capitalidade. Rio de Janeiro: Depto. Cultural/NAPE/UERJ, 2002.

ROLLEMBERG, Denise. Exílio: entre raízes e radares. Rio de Janeiro: Record, 1999.

SCHORSKE, Carl E. Viena fin-de-siécle: política e cultura. São Paulo: Companhia das Letras, 1990.

VASCONCELOS, Pe. Simão de. Sermão... Lisboa: Henrique Valente de Oliveira (Ed.), 1663.

VIANY, Alex. O processo do Cinema Novo. Rio de Janeiro: Aeroplano, 1999.

VIENNE, Patrick. You are here: la ville en plan d'ensemble dans le cinéma américain contemporain. In: BARILLET, Julie et al (orgs). La ville au cinéma. Artois: Artois Presses Université. 2005.

XAVIER, Ismail. O cinema brasileiro moderno. São Paulo: Paz e Terra, 2001.

Sertão mar: Glauber Rocha e a estética da fome. São Paulo: Cosac Naify, 2007.

\section{Resumo}

A proposta do artigo é evidenciar o embate entre o Cinema Novo e o governo de Carlos Lacerda (1960-1965) em torno da representação cinematográfica do Rio de Janeiro. Recorre-se à análise de $A$ grande cidade (Cacá Diegues, 1966) para, através dela, evidenciar a disputa entre a representação crítica da modernidade - pautada pelos pressupostos do cinema político - e a defesa de 
uma imagem urbana utópica, baseada na noção de capitalidade e levada a cabo por processos de modernização.

Palavras-chave: Cinema Novo; representação; Estado da Guanabara; cinema urbano.

\section{Abstract}

This paper aims to elucidate the struggle between Cinema Novo and Carlos Lacerda's government (1960-1965) regarding the cinematographic representation of Rio de Janeiro. On this purpose, Cacá Diegues' A grande cidade (1966) is analyzed, in order to explicit the dispute between the critical representation of modernity - based on the principles of the political cinema - and the defense of an utopian urban image, based on the notion of capitality and materialized through modernization processes. Key words: Cinema Novo; representation; State of Guanabara; urban cinema.

\section{Resumé}

Le but de cet article est d'éclairer le conflit entre le Cinema Novo et le gouvernement de Carlos Lacerda (1960-1965) à propos de la représentation cinématographique de Rio de Janeiro. L'article s'appuie sur l'analyse du film A grande cidade (Cacá Diegues, 1966) pour évidencier l'opposition entre la représentation critique de la modernité - guidé par des hypothèses du cinéma politique - et la défense d'une image urbaine utopique, fondée sur la notion de capitalité et produite par un processus de modernisation.

Mots clés: Cinema Novo; représentation; État de Guanabara; cinéma urbain. 